\title{
Auf der sicheren Seite ...
}

Rechtssicherheit streben Unternehmen jeglicher Größenordnung an. Der Fleiß der Gesetzgeber rund um den Globus, beständig Vorschriften und Regularien anzupassen oder gar ganz neu zu beschließen, sorgt dafür, dass dies eine immerwährende Aufgabe bleibt. Unternehmen sind unter anderem in den Bereichen Datenschutz, Lizenzrecht oder Urheberrecht unmittelbar betroffen. Sehr häufig bewegen sie sich in rechtlichen Grauzonen, ohne sich dessen bewusst zu sein. Vieles, was eigentlich klar geregelt sein sollte, ist es bei genauerem Hinsehen keineswegs - der Interpretationsspielraum ist oft gewaltig, wie Gerichtsurteile immer wieder ein-

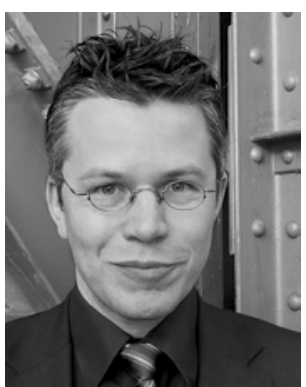

Peter Pagel

Chefredakteur

drucksvoll belegen.

Hinzu kommen neue Herausforderungen, die etwa durch den Erfolg der sozialen Netzwerke wie zum Beispiel Facebook entstehen. Was sollte man seinen Mitarbeitern erlauben, was möchte man vielleicht gerne gestatten, geht damit aber erhebliche Risiken für das Unternehmen ein? Die Unsicherheit ist bei solchen Fragen meist groß. In Gesprächen mit Fachleuten, mit Fachartikeln und Kommentaren gehen wir in unserem aktuellen Schwerpunkt „IT \& Recht“ diesen Belangen nach. Wir hoffen, damit einen kleinen Beitrag leisten zu können, dass Sie sich etwas sicherer fühlen im Dschungel der Gesetze und Verordnungen oder zumindest ein Bewusstsein dafür entwickeln, wo mögliche Gefahrenquellen liegen.

Viele Grüße,

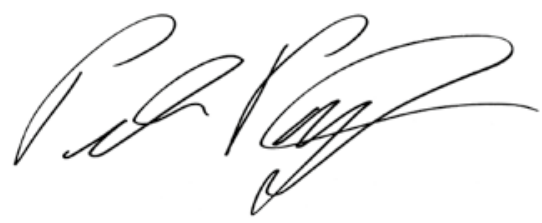

Peter Pagel, Chefredakteur 